ment panel, has worked with the council to develop the certification system. "We're trying to build something that we both see as beneficial," says Barbara Best, a member of a task force subgroup that has drafted a proposal for new legislation for the aquarium industry.

The task force wants a separate set of certification guidelines that would probably be broadly similar to that of the MAC. Importers would have to state that their products were obtained according to the guidelines. Although the United States would not monitor collection, evidence from government or other sources abroad would lead to prosecution, with penalties for falsifying documents.

The task force and the MAC differ on some points. For instance, the proposed legislation calls for the identification of species that should not be imported because of factors such as low survival rate in transit or soon after purchase. Trade in these species would then be banned.

Holthus says this would be premature, as the data are not available on which to make an informed choice. The first priority, he says, is to generate such data.

The current plan calls for certified animals to be offered to key markets in the United States, the largest importer of marine aquarium animals, beginning in about September 2001

\title{
... as scientists raise alarm over coral reefs
}

Peter Pockley, Bali

Unusually for a specialist research conference, last week's ninth International Coral Reef

Symposium in Bali, Indonesia, has pushed scientists to the forefront of the public debate on the effects of climate change on coral reefs at local, regional and international levels.

A consensus statement was triggered by an impassioned call from Yossi Loya, a veteran coral researcher from Israel's Tel Aviv University and winner of the Darwin Medal of the International Society for Reef Studies: "As a coral reef society we must add our voice to the growing international concern on the issue of global climate change, and call for an effective reduction in greenhouse gas emissions over the next decade."

After being given evidence for the dramatic decline of the world's reefs (see Nature 407, 932; 2000), the 1,430 delegates felt they could not wait the four years to the next symposium, in Okinawa, Japan, before raising the alarm. Even those who only a year ago were sceptical that global warming is linked directly to mass bleaching events among corals have joined the chorus.

A scientific panel of symposium chairs and key speakers from four nations concluded: "Reefs face a bleak future as all climate models show that current increases in sea temperature will continue."

The panel agreed that there is "insufficient evidence that corals are able to acclimatize or adapt fast enough to these sort of changes," and nominated this as a priority area for research. But they added: "It seems perilous to use this as reason for little or moderated action."

But many delegates insisted that destructive fishing practices are both more influential and more immediately manageable than global warming. Concerned that the issue might be forced to take a back seat to what they see as the 'sexy' issue of global warming, Mark Erdmann of the US Agency for International Development, among others, presented evidence that blast and cyanide fishing are "indisputably the biggest threats to coral reefs" off Indonesia (see opposite).

Erdmann says failure to apply strict regulations against these practices is costing Indonesia more than US\$200 million annually and threatens the world's greatest coral biodiversity.

In an unexpectedly frank speech, Indonesia's VicePresident Megawati Sukarnoputri admitted that only $6.5 \%$ of reefs in the Indonesian archipelago are "still in good condition", and a large part of the rest are "gravely damaged".

The case for urgent action will be taken directly to Washington and New York next month by Clive Wilkinson of the Australian Institute of Marine Science. 